\title{
Long-term trend analysis and climatology of tropical cirrus clouds using 16 years of lidar data set over Southern India
}

\author{
A. K. Pandit ${ }^{1}$, H. S. Gadhavi ${ }^{1}$, M. Venkat Ratnam ${ }^{1}$, K. Raghunath ${ }^{1}$, S. V. B. Rao ${ }^{2}$, and A. Jayaraman ${ }^{1}$ \\ ${ }^{1}$ National Atmospheric Research Laboratory, Gadanki-517 112, A. P., India \\ ${ }^{2}$ Department of Physics, Sri Venkateswara University, Tirupati-517502, A.P., India \\ Correspondence to: H. S. Gadhavi (harish@narl.gov.in, harish.gadhavi@gmail.com)
}

Received: 14 April 2015 - Published in Atmos. Chem. Phys. Discuss.: 12 June 2015

Revised: 1 November 2015 - Accepted: 12 November 2015 - Published: 16 December 2015

\begin{abstract}
Sixteen-year (1998-2013) climatology of cirrus clouds and their macrophysical (base height, top height and geometrical thickness) and optical properties (cloud optical thickness) observed using a ground-based lidar over Gadanki $\left(13.5^{\circ} \mathrm{N}, 79.2^{\circ} \mathrm{E}\right)$, India, is presented. The climatology obtained from the ground-based lidar is compared with the climatology obtained from 7 and a half years (June 2006December 2013) of Cloud-Aerosol Lidar with Orthogonal Polarization (CALIOP) observations. A very good agreement is found between the two climatologies in spite of their opposite viewing geometries and the differences in sampling frequencies. Nearly $50-55 \%$ of cirrus clouds were found to possess geometrical thickness less than $2 \mathrm{~km}$. Ground-based lidar is found to detect a higher number of sub-visible clouds than CALIOP which has implications for global warming studies as sub-visible cirrus clouds have significant positive radiative forcing. Cirrus clouds with mid-cloud temperatures between -50 to $-70^{\circ} \mathrm{C}$ have a mean geometrical thickness greater than $2 \mathrm{~km}$ in contrast to the earlier reported value of $1.7 \mathrm{~km}$. Trend analyses reveal a statistically significant increase in the altitude of sub-visible cirrus clouds which is consistent with the recent climate model simulations. The mid-cloud altitude of sub-visible cirrus clouds is found to be increasing at the rate of $41 \pm 21 \mathrm{~m}_{\text {year }}{ }^{-1}$. Statistically significant decrease in optical thickness of sub-visible and thick cirrus clouds is observed. Also, the fraction of sub-visible cirrus cloud is found to have increased by $9 \%$ in the last 16 years (1998 to 2013). This increase is mainly compensated by a $7 \%$ decrease in thin cirrus cloud fraction. This has implications for the temperature and water vapour budget in the tropical tropopause layer.
\end{abstract}

\section{Introduction}

Cirrus clouds are ubiquitous, high altitude, thin and wispy cold clouds predominantly consisting of non-spherical ice crystals. They exhibit a very high degree of spatio-temporal variability in their macrophysical, microphysical and optical properties (Liou, 1986; Lynch et al., 2002). These clouds affect the earth's radiation budget through two competing radiative effects viz., albedo effect (by reflecting back the incoming shortwave solar radiation) and green-house effect (by trapping the outgoing long-wave terrestrial radiation) (Liou, 2005). The former effect causes cooling while the latter causes warming. The magnitude of these radiative effects are strong functions of optical and macrophysical (cloud coverage, altitude, thickness) properties. The optical properties are in turn strong function of microphysical (amount, size, shape and orientation of ice-crystals) properties (Liou, 1986, 2005). Overall, cirrus clouds are found to have net positive radiative forcing (Chen et al., 2000; Hartmann et al., 1992) at the top of the atmosphere (TOA) and thus they warm the climate system. However, these estimates are based on the International Satellite Cloud Climatology Project (ISCCP) cloud data obtained from passive satellites that do not consider the overlap effect of multi-layered clouds. This overlap effect is the largest source of uncertainty in estimating the long-wave radiative fluxes (Stephens et al., 2004) and cannot be neglected in tropics where the occurrence of multi-layered cirrus clouds is the highest (Nazaryan et al., 2008). This difficulty can be overcome only by using ground and space-based lidars that provide vertical distribution of clouds with opposite viewing geometry. 
For decades, the representation of cirrus clouds and their processes in the climate models is found to be challenging, partly owing to the lack of fundamental details of cloud microphysical processes and partly due to the inability to resolve small-scale processes in a General Circulation Model (GCM) grid box (Boucher et al., 2013 and references therein). For instance, still the cloud feedback from thin cirrus cloud (which causes net warming) amount is unknown which results in a substantial uncertainty in the climate model predictions. Essentially, this demands highly stable, accurate, precise and long-term observations from ground- and space-based lidars to understand the processes and validate the models.

Cirrus clouds that cover about $50 \%$ of the globe with highest fraction over the tropics (Stubenrauch et al., 2010, 2013) have strong potential to impact the regional (especially the tropics) and global climate. It is well-known that water vapour, low temperature and ice nuclei (for heterogeneous freezing) are the main ingredients needed for the formation of cirrus clouds. Recent research shows that the stratospheric water vapour which mainly comes from the tropical tropopause layer (TTL) has been increasing (Rosenlof et al., 2001; Solomon et al., 2010) and this increase is closely associated with the changes in the tropopause temperature (Randel and Jensen, 2013). In addition to this, aerosols in the TTL, some of which serve as ice nuclei are increasing (Kulkarni et al., 2008; Vernier et al., 2015) especially during the monsoon season over south-east Asia. Latitudinal changes in the distribution of water vapour, temperature and aerosols will affect the distribution of TTL cirrus clouds (Massie et al., 2013) and ultimately affect the Earth's radiation balance. Thus, it is essential to quantify the properties of TTL cirrus clouds and their dependence on geographic locations, temperature (altitude) and aerosol composition which necessitate long-term observations (Randel and Jensen, 2013).

Several modelling studies have suggested that a warming climate will affect cirrus cloud properties such as altitude and thickness (Boucher et al., 2013 and references within; Chepfer et al., 2014). Long-term observations of vertically resolved properties of cirrus clouds can help in early detection of climate change or validate climate models.

Despite the continuous efforts made to minimize the uncertainties in cirrus cloud properties at regional and global scales through ground-based, space-based and in-situ observations, regional climatologies of tropical cirrus clouds on the decadal timescale are very few. All these facts strongly encourage us to build a detailed cirrus cloud climatology based on 16 years (1998-2013) of ground-based lidar data and 7 and a half years (June 2006-December 2013) of Cloud-Aerosol Lidar with Orthogonal Polarization (CALIOP) aboard Cloud-Aerosol Lidar and Infrared Pathfinder Satellite Observations (CALIPSO) data over Gadanki $\left(13.5^{\circ} \mathrm{N}, 79.2^{\circ} \mathrm{E}\right)$, a tropical location in South Asia. Note that CALIOP has a narrow swath and repeat-cycle of the order of 16 days in tropics. It is essential to understand whether such low temporal resolution data capture major cloud variability or not. Further, there are few advantages and disadvantages of both ground-based and space-borne lidars. While the ground-based (space-borne) lidars have excellent vertical and temporal (spatial) resolution for obtaining cirrus properties, they suffer from poor spatial (temporal) resolution. Further, no information on cirrus clouds can be obtained using ground-based lidar during cloudy conditions while space-borne lidars do not have such restrictions as they are being viewed from the top. Thus, both ground-based and space-borne lidars supplement each other. However, as the two lidars have different viewing geometry and sampling frequency, it is important to investigate whether these factors affect long-term climatology.

In this paper, we report analysis of the 16-year climatology of macrophysical (base height, top height and geometrical thickness) and optical properties (cloud optical thickness) of cirrus clouds observed using a ground-based lidar at Gadanki. We compare this climatology with that obtained from CALIOP observations (during 2006-2013). The dependence of cirrus cloud geometrical and optical thickness on mid-cloud temperature is also investigated. In addition to this, we also investigate the long-term trends in the properties of sub-visible, thin and thick cirrus clouds using both lidars.

\section{Instruments and data used}

\subsection{NARL lidar}

For this study, we have used 16 years (1998-2013) of data from a ground-based lidar situated at the National Atmospheric Research Laboratory (NARL), Gadanki $\left(13.5^{\circ} \mathrm{N}\right.$, $79.2^{\circ} \mathrm{E}$ ). To the best of our knowledge, this is the longest duration of a ground-based lidar data set ever used for obtaining cirrus cloud climatology over a tropical station. The detailed site description and system specifications of the lidar (hereafter called NARL lidar) are reported in our earlier study (Pandit et al., 2014). A brief description of the NARL lidar is presented here. The NARL lidar is a monostatic biaxial system which transmits Nd: YAG laser pulses of wavelength $532 \mathrm{~nm}$ at a rate of $20 \mathrm{~Hz}(50 \mathrm{~Hz}$ since 2007). Each pulse has a pulse energy of $550 \mathrm{~mJ}(600 \mathrm{~mJ}$ since 2007) and a pulse duration of $7 \mathrm{~ns}$. The backscattered photons are collected by a Schmidt-Cassegrain telescope attached with two identical orthogonally aligned photomultiplier tubes (PMTs). Photon counts are accumulated in $300 \mathrm{~m}$ resolution bins and integrated for $4 \mathrm{~min}$. Lidar data were collected only during the nights that are free from low-level clouds and rain. This limits the observation time during the cloudy nights especially during the summer monsoon season (June-September) when the sky is mostly covered with thick low-level clouds. Lidar profiles were rigorously quality checked based on signal to noise ratio before using them in cirrus cloud statistics. A to- 
tal of 41280 profiles qualified for building the cirrus cloud climatology.

\subsection{CALIPSO cloud products}

CALIPSO is an integral part of the afternoon-train (called A-train) constellation of satellites dedicated to the synergistic observation of aerosols and clouds over the entire globe. Since its launch on 28 April 2006, CALIPSO has been consistently providing high-quality vertical distribution of aerosol and cloud properties at unprecedented resolution and accuracy (Young and Vaughan, 2009). This has significantly improved our understanding of aerosols and clouds globally. In order to compare the properties of cirrus clouds obtained from NARL lidar, we have used level-2, $5 \mathrm{~km}$ cloud layer and cloud profile (Version 3.01, 3.02 and 3.03) data products obtained from CALIOP aboard CALIPSO. Here, the attribute $5 \mathrm{~km}$ implies $5 \mathrm{~km}$ horizontal resolution along the satellite track at ground level. CALIOP is a near-nadir viewing space-based, dual-wavelength, dual-polarization, three channel elastic backscatter lidar that transmits linearly polarized laser pulses having an average pulse energy of $110 \mathrm{~mJ}$ both at first $(1064 \mathrm{~nm})$ and second harmonic $(532 \mathrm{~nm})$ wavelengths of Nd: YAG laser (Winker, 2003; Hunt et al., 2009; Winker et al., 2009). The specifications of both NARL lidar and CALIOP are compared in Table 1. The backscattered signal is received by a $1 \mathrm{~m}$ diameter telescope with parallel and perpendicularly polarized channels at $532 \mathrm{~nm}$ wavelengths and one parallel channel at $1064 \mathrm{~nm}$.

It is well-known that the properties of cirrus clouds exhibit significant spatial and temporal variations (Liou, 1986). In order to obtain the best spatio-temporal concurrent observations with respect to NARL lidar observations, CALIOP overpasses within $50 \mathrm{~km}$ radius from Gadanki are considered for the period from June 2006 to December 2013. Both day and night-time data are used for obtaining cirrus cloud climatology near Gadanki. The nearest night-time CALIOP overpass takes place at around 20:33 UTC (02:03 LT) which is about $11 \mathrm{~km}$ away from Gadanki whereas the nearest day time CALIOP overpass takes place at around 08:21 UTC (13:51 LT) which is about $34 \mathrm{~km}$ away from Gadanki. The proximity of CALIOP night-time overpasses to Gadanki provides us a unique opportunity to study the properties of cirrus clouds simultaneously using ground-based and space-borne lidars over a tropical station with opposite viewing geometry. Two such nocturnal observations of cirrus clouds over Gadanki obtained using NARL lidar and CALIOP on 1920 November 2008 and 3-4 December 2013 are depicted in Fig. 1, detailed properties of them are presented in the next section. The red circle in the CALIOP vertical feature mask (VFM) in Fig. 1c and $\mathrm{h}$ shows the clouds present in the proximity of Gadanki. Because of the 16 days repeat cycle of CALIOP, four overpasses at most can be obtained in each month, with 2 daytime and 2 night-time overpasses. During the period from June 2006 to December 2013, a total number of 146 (151) data files are collected during the day (night) in the region selected around Gadanki which contained a total number of 2906 (3022) profiles, out of which 1820 (1876) profiles were day (night) time cloudy profiles (Table S1 in the Supplement).

\subsection{NCEP FNL air temperature data}

For the estimation of extinction coefficient and hence the optical thickness of cirrus cloud layers, pressure and temperature $(p-T)$ profiles over Gadanki during the lidar observation time are required. Since, daily $p-T$ profiles are available only at 12:00 GMT (17:30 LT) over Gadanki from the daily radiosonde launches since 2006, we used 6-hourly air temperature (at 26 pressure levels) from NCEP FNL $1^{\circ} \times 1^{\circ}$ data interpolated from the period of 1999-2013 to have nearsimultaneous temperature observations over Gadanki during the lidar observation time. For the year 1998 when no NCEP FNL data are available, monthly mean temperature profiles were used for the estimation of the molecular backscattering coefficient. These data were obtained from the website http://rda.ucar.edu/datasets/ds083.2/. Same temperature profiles are used for finding the relation between the cirrus cloud properties and temperature.

\section{Methodology}

\subsection{Cirrus cloud detection and percentage occurrence}

Cirrus clouds observed using NARL lidar data are detected by using Wavelet Covariance Transform (WCT) method as described in Pandit et al. (2014). Briefly, the cloud-detection algorithm uses Haar wavelet with dilation 3 and altitudedependent threshold. The threshold varying with altitude has the benefit of low noise in near range and less false detection at far range. Further to avoid false detection, if raw photon counts at cloud layer are not greater than mean background plus 3 times the standard deviation then those profiles are excluded. Cloud base and top heights of five different layers can be obtained very accurately using this method. The lowest physical thickness that NARL lidar could detect is $600 \mathrm{~m}$. To distinguish cirrus cloud layer from other clouds, we used a temperature threshold. Only those cloud layers with a base temperature below $-20^{\circ} \mathrm{C}$ (which corresponds to a base height above $8 \mathrm{~km}$ ) are considered as cirrus cloud layer in this study. Cloud layer boundaries in the attenuated backscattered signal acquired by CALIOP are detected by a Selective, Iterative Boundary Location (SIBYL) algorithm described in Vaughan et al. (2009). This algorithm finds the aerosol and cloud layers (called features) and detects their boundaries. We have used same temperature criterion as for NARL lidar to identify cirrus clouds in CALIOP data.

To know the effects of cirrus clouds on regional climate, it is essential to know how frequent these clouds occur over a given region (especially over the tropical regions) during dif- 
Table 1. Specifications of NARL-lidar and CALIOP.

\begin{tabular}{|c|c|c|}
\hline Characteristics & NARL lidar & CALIOP \\
\hline Operating Wavelength(s) & $532 \mathrm{~nm}$ & $532,1064 \mathrm{~nm}$ \\
\hline Average pulse energy & $\begin{array}{l}550 \mathrm{~mJ}(1998-2006) \\
600 \mathrm{~mJ}(2007-2013)\end{array}$ & $110 \mathrm{~mJ}$ \\
\hline Pulse width & $7 \mathrm{~ns}$ & $20 \mathrm{~ns}$ \\
\hline Pulse repetition rate & $\begin{array}{l}20 \mathrm{~Hz}(1998-2006) \\
50 \mathrm{~Hz}(2007-2013)\end{array}$ & $20.16 \mathrm{~Hz}$ \\
\hline Telescope diameter & $35.5 \mathrm{~cm}$ & $100 \mathrm{~cm}$ \\
\hline Receiver field of view & $1 \mathrm{mrad}$ & $130 \mu \mathrm{rad}$ \\
\hline Detectors & Photomultiplier Tube (PMT) & $\begin{array}{l}\text { PMT for } 532 \mathrm{~nm} \\
\text { Avalanche photodiode for } 1064 \mathrm{~nm}\end{array}$ \\
\hline Polarization & Co and cross-polarized* & $\begin{array}{l}\text { Co and cross-polarized for } 532 \mathrm{~nm} \\
\text { Co-polarized for } 1064 \mathrm{~nm}\end{array}$ \\
\hline Vertical resolution & $300 \mathrm{~m}$ & $\begin{array}{l}30 \mathrm{~m} \text { for altitude range }-0.5 \text { to } 8.2 \mathrm{~km} \\
60 \mathrm{~m} \text { for altitude range } 8.2 \text { to } 20.2 \mathrm{~km}\end{array}$ \\
\hline Horizontal resolution & Stationed & $\begin{array}{l}0.333 \mathrm{~km} \text { for altitude range }-0.5 \text { to } 8.2 \mathrm{~km} \\
\text { along the track } \\
1 \mathrm{~km} \text { for altitude range } 8.2 \text { to } 20.2 \mathrm{~km} \\
\text { along the track }\end{array}$ \\
\hline
\end{tabular}

* only co-polarized data of $532 \mathrm{~nm}$ channel are used.

ferent months and seasons in a year. For this, the percentage occurrence (PO) of cirrus clouds at each altitude bin for both NARL lidar and CALIOP cloud layer data sets is calculated by taking the ratio of number of profiles with cirrus clouds at that bin to total number of profiles (Pandit et al., 2014).

\subsection{Macrophysical and thermodynamical properties of cirrus clouds}

Macrophysical properties of cirrus clouds viz., cirrus base, top, mid-cloud altitude, geometrical thickness and its distance from the tropopause are obtained from both lidar data sets. Mid-cloud altitude of each cloud layer is taken as midpoint between the base and top altitude for that layer. Base and top altitudes of cloud layers are provided directly in CALIOP $5 \mathrm{~km}$ cloud layer data files. The geometrical thickness of cirrus clouds is obtained by subtracting the cirrus base altitude from cirrus top altitude. Distance from the tropopause of each cirrus cloud layer in case of NARL lidar is obtained by subtracting the cirrus mid-cloud altitude from the tropopause height provided in the FNL data which uses lapse-rate tropopause definition of WMO. We have used temperature profiles and tropopause height present in CALIOP cloud data products which are originally derived from GEOS-5 data product provided by the Global Modelling and Assimilation Office (GMAO).

\subsection{Optical properties of cirrus clouds}

Kaestner's lidar inversion method (Kaestner, 1986) has been used for the retrieval of the extinction coefficient $(\alpha)$. The extinction profile integrated between cloud base and the top is used to obtain optical thickness of cirrus cloud layers. Molecular backscattering coefficient at $532 \mathrm{~nm}$ wavelength is calculated using the pressure and temperature data obtained from NCEP FNL data. Lidar ratio for cirrus clouds is assumed to be constant with altitude and season with a value of 25 sr following CALIOP extinction retrieval algorithm (Young et al., 2013; Young and Vaughan, 2009). The effect of multiple scattering which is a function of laser penetration depth, cloud range (or height), receiver field of view (FoV), size and shapes of ice-crystals (Eloranta, 1998) cannot be neglected in the measurement of cirrus cloud properties using a lidar with a receiver FoV of $1 \mathrm{mrad}$. Several studies (Chen et al., 2002; Chepfer et al., 1999; Hogan, 2006; Sassen and Cho, 1992; Sassen and Comstock, 2001) have suggested different values of multiple scattering correction factor $(\eta)$ ranging from 0.1 to 0.9 based on different crystal habits and optical properties of cirrus clouds. In this study, the effect of multiple-scattering is taken care of by assuming $\eta=0.75$ following Sassen and Cho (1992) and Sassen and Comstock (2001). Sassen and Cho (1992) used telescope with field of view $3 \mathrm{mrad}$ which is comparable to our telescope. Sassen and Comstock (2001) used three different values of $\eta$ depending on cloud type which are 0.6 to 0.7 for thick clouds, 0.8 for thin clouds and 0.9 for sub-visible cirrus cloud. We have used single value 0.75 for all the cloud types instead. In case of CALIOP, $\eta=0.6$ is being used in retrieval algorithm of the extinction coefficient (Young et al., 2013; Young and Vaughan, 2009). The reference altitude used in the retrieval of extinction coefficient is $25 \mathrm{~km}$ for NARL lidar. 

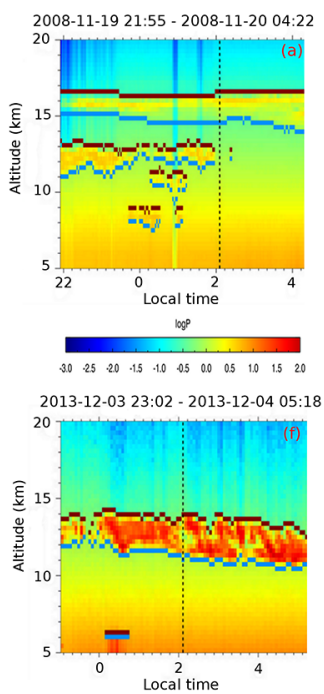
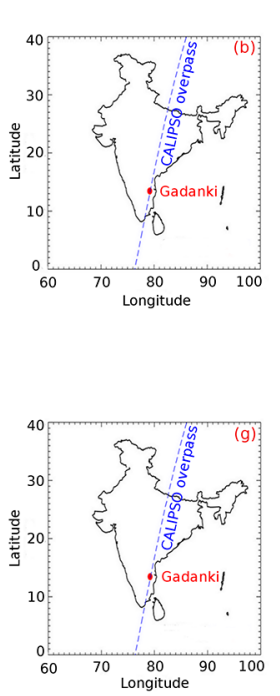

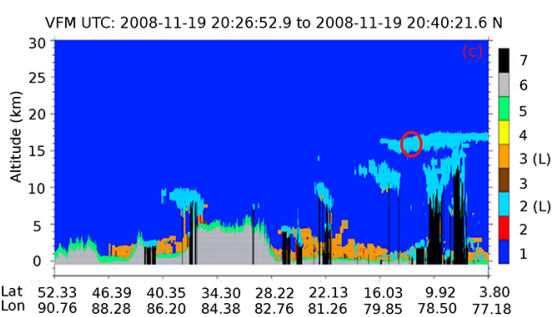

$1=$ clear air $2=$ cloud $3=$ aerosol $4=$ stratospheric layer $5=$ surface $1=$ clear air $2=$ cloud $3=$ aerosol $4=$ stratospheric layer 5
$6=$ subsurface $7=$ totally attenuated $L=$ low/no confidence

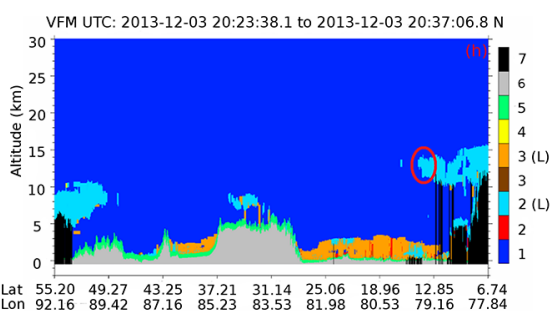

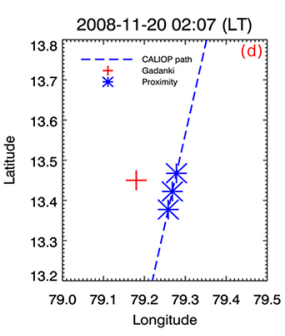
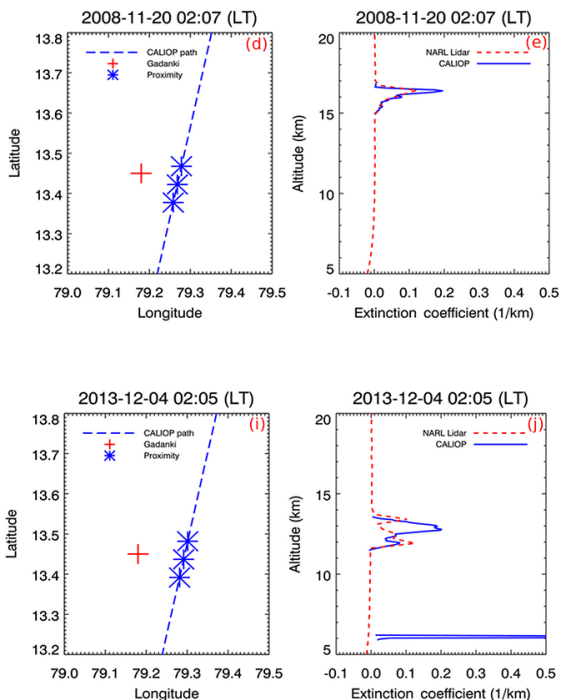

Figure 1. (a) Night-time evolution of cirrus clouds as a function of altitude observed on 19-20 November 2008 using NARL Lidar. Colour scale represents the logarithm of the normalized photon counts. Cirrus base and top altitudes are shown with blue and brown lines, respectively. Black dashed vertical line shows the CALIPSO overpass time near Gadanki. (b) Overpass trajectory of CALIPSO (shown by dashed blue line) near Gadanki (shown by filled red circle). (c) Colours show the vertical feature mask (VFM) along the CALIPSO track as a function of altitude on 20 November 2008. The red circle shows the clouds sampled near Gadanki. (d) Overpass trajectory of CALIPSO (dashed blue line) at around 02:07 LT on 20 November 2008 near Gadanki (red plus symbol). Blue asterisks correspond to the proximate CALIOP profiles used for averaging, (e) averaged extinction coefficient profiles obtained from NARL Lidar (dashed red line) and CALIOP (solid blue line). (f) to (j) are same as (a) to (e) respectively but for the observations on 3-4 December 2013.

Optical thickness $\left(\tau_{\text {cloud }}\right)$ of cirrus cloud layer is derived using the expression

$\tau_{\text {cloud }}=\int_{z_{\mathrm{b}}}^{z_{\mathrm{t}}} \alpha(z) \mathrm{d} z$,

where $\alpha(z)$ is the extinction coefficient of a cirrus cloud layer with $z_{\mathrm{b}}$ and $z_{\mathrm{t}}$ as its base and top altitudes, respectively.

For the retrieval of particulate extinction coefficient profiles obtained from the attenuated backscattered data acquired by CALIOP, the fully automated retrieval algorithms called Hybrid Extinction Retrieval Algorithms (HERA) are being used (Young and Vaughan, 2009). Once the features (aerosol and cloud layers) are identified by Scene Classification Algorithm (SCA), their lidar ratio is estimated using the transmission method (Young, 1995). When transmission method fails, initial lidar ratio is assigned based on the feature type, for example lidar ratio of $25 \mathrm{sr}$ is chosen for cirrus clouds. HERA is then invoked to compute the extinction coefficient profiles using the profile solver (Young and Vaughan, 2009), which is then integrated to obtain cloud optical depth. We use the variable named feature optical depth from the CALIOP level-2 data product which provides optical depths for ten cloud layers. Only those features for which Cloud-Aerosol Discrimination (CAD) score lies between 80 and 100 and are located below $-20^{\circ} \mathrm{C}$ are considered as cirrus cloud layers. Features with negative values of optical depth are excluded from the statistics of cirrus optical properties. Figure 1e and j illustrate two cases where extinction profile of cirrus cloud layer observed on two different nights (20 November 2008 and 4 December 2013) over Gadanki using NARL lidar is compared with the concurrent extinction profiles obtained from CALIOP cloud profile data. For comparison with the NARL lidar, we averaged three proximate CALIOP profiles shown by blue asterisks in Fig. 1d and i. For both nights, the base and top altitudes of cirrus cloud layer from NARL lidar and CALIOP show a very good agreement. Also, the cloud layer structure on 20 November 2008 in both lidars show good similarity. However, the structure of cirrus cloud layer on 4 December 2013 and the magnitude of extinction coefficient in both cases are different which may be due to the spatial inhomogeneity of the cloud structure. This can be seen clearly from the CALIOP vertical feature mask (VFM) for the two nights as shown in Fig. 1c and h. The various macrophysical and optical properties of cirrus cloud layer observed on these two nights are listed in Table 2. Overall the extinction coefficients and the cloud optical depths observed using NARL lidar are lower than CALIOP. However, the difference is not the same on two nights with 4 December 2013 night having larger differences. 
Table 2. Macrophysical and optical properties of cirrus cloud layer detected using NARL lidar and CALIOP on 19-20 November 2008 and 3-4 December 2013.

\begin{tabular}{lrrrr}
\hline Date & 19-20 November 2008 & 3-4 December 2013 \\
\hline Characteristics & NARL lidar & CALIOP & NARL lidar & CALIOP \\
\hline Local Time & $02: 07: 38$ & $02: 07: 48$ & Average of 02:02 and 02:06 & $02: 05: 00$ \\
Cloud base altitude $(\mathrm{km})$ & 14.91 & 14.94 & 11.62 & 11.53 \\
Mid-cloud altitude $(\mathrm{km})$ & 15.81 & 15.90 & 12.67 & 12.55 \\
Cloud top altitude $(\mathrm{km})$ & 16.71 & 16.86 & 13.72 & 13.56 \\
Geometrical thickness $(\mathrm{km})$ & 1.80 & 1.92 & 2.10 & 2.03 \\
Tropopause height $(\mathrm{km})$ & 16.41 & 16.66 & 16.44 & 16.51 \\
Distance from tropopause $(\mathrm{km})$ & -0.60 & -0.76 & -3.77 & -3.96 \\
Average layer extinction coefficient $\left(\mathrm{km}^{-1}\right)$ & 0.03 & 0.05 & 0.53 & 0.88 \\
Cloud Optical Depth & 0.06 & 0.09 & 0.11 & 0.18 \\
\hline
\end{tabular}
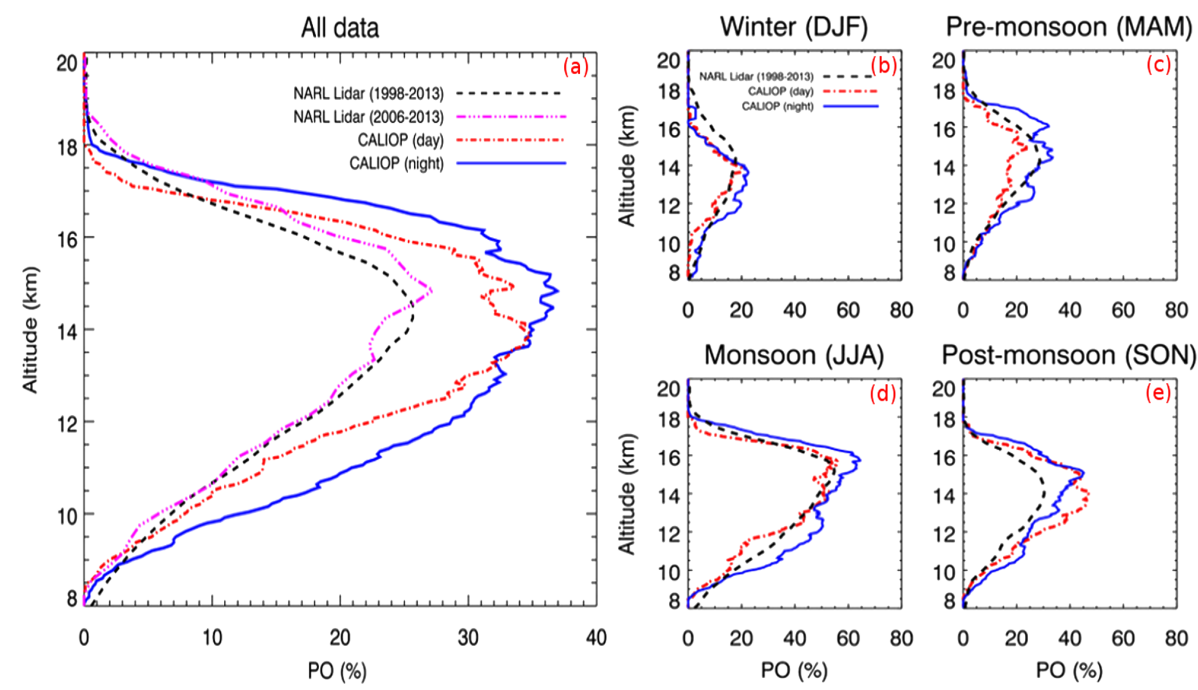

Figure 2. (a) Climatological altitude distribution of PO of cirrus clouds obtained from NARL Lidar data for the period 1998-2013 (dashed black line), NARL Lidar data during half an hour time window centred at 02:03 LT for the period 2006-2013 (triple dotted-dashed magenta line), CALIOP daytime (single dotted dashed red line) and CALIOP night-time (solid blue line) data sets for the period 2006-2013. (b) Same as (a) but for winter (DJF), (c) pre-monsoon (MAM), (d) monsoon (JJA), and (e) post-monsoon (SON) seasons.

\section{Results and discussion}

\subsection{Occurrence of cirrus clouds over Gadanki: climatology}

The climatological altitude distribution of PO of cirrus clouds for the entire 16 years (1998-2013) irrespective of sampling time is shown with a dashed black line in Fig. 2a. The PO peaks at $14.5 \mathrm{~km}$ with a value of $25 \%$. Altitude distribution of PO based on CALIOP data has relatively broader peak with structures. The altitude of peak PO based on CALIOP data is in good agreement with NARL lidar; however, magnitude of peak PO differs significantly with CALIOP having higher values. To investigate whether the difference in time range (16 years vs. 7.5 years) or time of observation (entire night vs. fixed overpass) is responsible for differences in PO based on NARL lidar and PO based on
CALIOP, a subset of entire NARL lidar data set for the period 2006-2013 is made. This data subset contains lidar data acquired only during the half an hour time window centred at 02:03 LT (mean local time for CALIOP night-time overpass near Gadanki). The PO of cirrus clouds based on sub-set NARL lidar data is shown with a triple-dotted dashed magenta line in Fig. 2a. The altitude distribution of PO based on subset data has a slightly better agreement with the altitude of peak PO values based on CALIOP. However, the difference in magnitude between the two PO distributions is still large. This can be attributed to the limited NARL lidar observation time during the cloudy nights especially during the monsoon season. For the sake of completeness, the PO distribution for the daytime CALIOP observations (shown by red single dotted-dashed line) is also compared with the other three PO distributions. CALIOP night-time PO distribution 
(a) NARL Lidar (1998 - 2013)

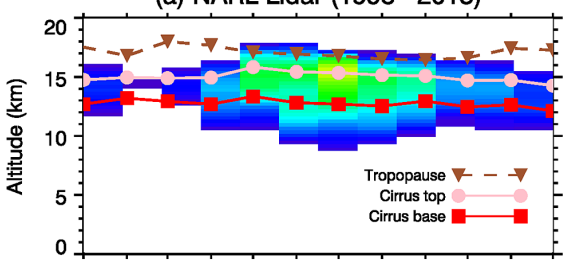

Jan Feb Mar Apr May Jun Jul Aug Sep Oct Nov Dec

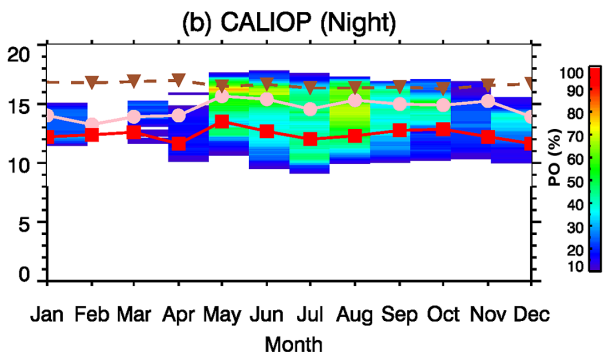

Figure 3. Filled contours show the climatological monthly mean variation of PO of cirrus clouds as a function of altitude over Gadanki (a) during 1998-2013 using NARL Lidar, (b) during 2006-2013 using CALIOP (night-time) data. Monthly mean tropopause height, cloud base height and cloud top height are shown by dashed brown lines with inverted triangles, red line with squares and pink line with filled circles, respectively.

is slightly larger than that during daytime at all the altitudes. This difference in PO is consistent with the results reported by Sassen et al. (2009) and Thorsen et al. (2013). This has been attributed to two reasons: one due to the day-night difference in the background noise level present in the backscattered signal from the CALIOP measurement and secondly, due to the day-night differences in cirrus cloud occurrence in tropics. The daytime background noise level present in the backscattered signal from the CALIOP measurement is larger than that during the night-time which prevents the detection of very thin cirrus cloud layers during the day. In addition to this, when the formation of cirrus clouds is associated with the development of deep-convective clouds which is quite common in tropics, then the frequency of occurrence of cirrus clouds during night and day will be different (Liu and Zipser, 2008; Sassen et al., 2009). Using Micro-pulse lidar observations over a tropical station Nauru Island $\left(0.52^{\circ} \mathrm{S}\right.$, $\left.166.92^{\circ} \mathrm{E}\right)$, Comstock et al. (2002, Fig. 5c) also found higher occurrence of cirrus clouds during evening and night hours than that during noon hours. It is not possible to exactly pinpoint which mechanism will be dominant for day and night PO difference at Gadanki with the limited data set which we have used in this study.

\subsection{Monthly and seasonal variation in PO of cirrus clouds}

The altitude distribution of monthly mean PO of cirrus clouds near Gadanki obtained from the 16 years of NARL lidar data and 7 and a half years of CALIOP night-time data are shown in Fig. 3a and b, respectively. Both exhibit enhanced PO in the altitude range of $9-17 \mathrm{~km}$ during MaySeptember owing to the increased convective activities in and around Gadanki. During this period, geometrically and optically thick cirrus clouds occur frequently near Gadanki region (Sunil Kumar et al., 2003; Martins et al., 2011; Pandit et al., 2014). The occurrence of multi-layered clouds is also high during this time (not shown here). All these factors are responsible for the spread of the PO distribution of clouds during these months. Here, we have not filtered NARL lidar data for 2 a.m. half an hour time window as very few profiles (less than 50) are available in that window during JuneAugust. The altitude of high PO obtained from both lidars is found above $14 \mathrm{~km}$ (Fig. 3a, b) during the months of MaySeptember. The monthly mean base and top altitudes of cirrus clouds (represented by filled red squares and filled pink circles superimposed on the colour contours) obtained from both lidars are consistent with each other (See Fig. 3a, b). We also observe a significant fraction of cirrus clouds occurring near and sometimes above the tropopause (shown by brown inverted triangles) during May-September months. This result is in good agreement with the observations of Pan and Munchak (2011, Fig. 7).

The seasonal variation in the altitude distribution of $\mathrm{PO}$ of cirrus clouds obtained from three (NARL lidar, CALIOP day and night) data sets is illustrated in Fig. 2b-e. Number of cloudy and total profiles for each season used for calculating PO for both data sets is provided in Table S1. During the winter season (Fig. 2b), the PO distribution above $15 \mathrm{~km}$ from NARL lidar data shows higher values than that of CALIOP data. The climatological PO (1998-2013) distribution from NARL lidar during the pre-monsoon season shows very good qualitative and quantitative match with the CALIOP night-time PO distribution (Fig. 2c). During the monsoon season (Fig. 2d), the number of lidar observations is the lowest. However, the climatological PO from NARL lidar for monsoon season matches well with the CALIOP PO distributions. Overall, we see a very good consistency between the two lidar systems in observing the seasonal occurrence of cirrus clouds in spite of opposite viewing geometry.

\subsection{Macrophysical and thermodynamic properties of cirrus clouds}

The histograms for the macrophysical properties (cirrus base, top and mid-cloud altitude, distance from tropopause, and geometrical thickness) and the thermodynamical property (mid-cloud temperature) of cirrus clouds are shown in Fig. 4 and their statistical details are listed in Table 3. The frequency distributions of cirrus base height from both lidars 
Table 3. Mean, median and standard deviation of macrophysical and thermodynamical properties of cirrus clouds obtained from NARL Lidar and CALIOP over Gadanki. Values in the parentheses represent the median.

\begin{tabular}{lrrr}
\hline Cirrus properties & NARL Lidar & CALIOP (night) & CALIOP (day) \\
\hline Base altitude $(\mathrm{km})$ & $13.0 \pm 2.2(13.1)$ & $12.5 \pm 2.2(12.6)$ & $12.8 \pm 2.0(12.7)$ \\
Top altitude $(\mathrm{km})$ & $15.3 \pm 2.0(15.5)$ & $14.9 \pm 2.1(15.3)$ & $14.5 \pm 2.0(14.9)$ \\
Mid-cloud altitude $(\mathrm{km})$ & $14.1 \pm 2.0(14.3)$ & $13.7 \pm 2.0(13.9)$ & $13.6 \pm 1.9(13.8)$ \\
Geometrical thickness $(\mathrm{km})$ & $2.3 \pm 1.3(1.8)$ & $2.4 \pm 1.7(1.8)$ & $1.7 \pm 1.2(1.3)$ \\
Mid-cloud temperature $\left({ }^{\circ} \mathrm{C}\right)$ & $-65.0 \pm 11.9(-67.6)$ & $-61.0 \pm 14.7(-63.6)$ & $-60.5 \pm 14.4(-63.2)$ \\
Distance from tropopause $(\mathrm{km})$ & $-2.6 \pm 2.1(-2.4)$ & $-2.8 \pm 2.0(-2.7)$ & $-2.8 \pm 1.9(-2.5)$ \\
\hline
\end{tabular}

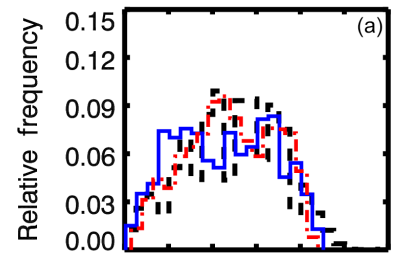

$8 \quad 1012 \quad 14 \quad 16 \quad 1820$

Cirrus base altitude $(\mathrm{km})$

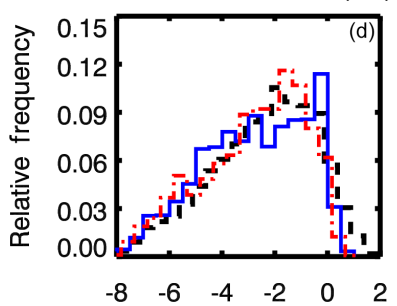

Distance from tropopause $(\mathrm{km})$

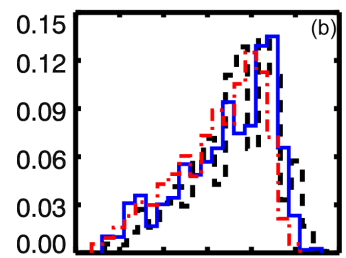

$\begin{array}{lllllll}8 & 10 & 12 & 14 & 16 & 18 & 20\end{array}$

Cirrus top altitude $(\mathrm{km})$

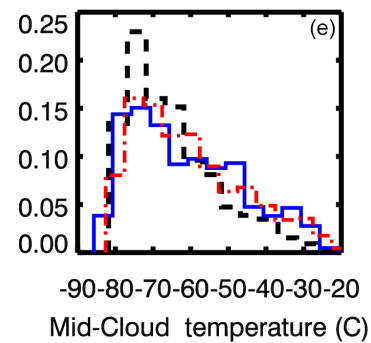

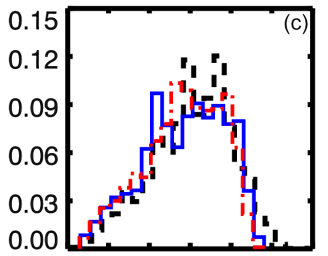

8101214161820
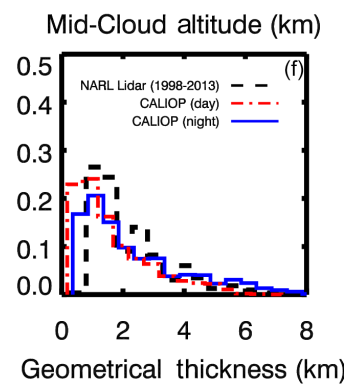

Figure 4. Histograms showing the frequency distribution of macrophysical properties of cirrus clouds viz. (a) base altitude, (b) top altitude, (c) mid-cloud altitude, (d) distance from the tropopause, (e) mid-cloud temperature, (f) geometrical thickness obtained from NARL Lidar (1998-2013) data (dashed black line), CALIOP daytime (single dot-dash red line) and CALIOP night-time (solid blue line) data sets. Bin size for (a)-(d) and (f) is $0.5 \mathrm{~km}$ while bin size for (e) is $5^{\circ} \mathrm{C}$.

show a good agreement (Fig. 4a). The distribution is spread out between 8 and $18 \mathrm{~km}$ such that it is difficult to pinpoint the most probable cirrus base altitude. Careful observation and comparison of cirrus base altitude distribution with that reported in Nazaryan et al. (2008, Fig. 6 in $20^{\circ} \mathrm{S}-20^{\circ} \mathrm{N}$ latitude bands) show that the most probable base altitude lies between 12 and $14 \mathrm{~km}$. Both NARL lidar and CALIOP histograms show a nearly one to one correspondence with each other in case of cloud top altitude (Fig. 4b) and midcloud altitude (Fig. 4c). The most probable top-altitude of cirrus clouds observed over Gadanki lies in the altitude range of $15-17 \mathrm{~km}$, which is very close to the tropopause. This is in good agreement with values reported by Comstock et al. (2002) over a tropical island (Nauru Island), who found it to be around $16 \mathrm{~km}$. However, it is little higher than values reported by Seifert et al. (2007) who found it to be in the range 13-15 km over Maldives (another tropical island). Both CALIOP and NARL data in Fig. 4d show that cirrus cloud observed over Gadanki lie very close to the tropopause. About $9 \%$ of them are found above the tropopause. CALIOP observations show a lower number of cases of cirrus clouds above the tropopause. Pan and Munchak (2011) have shown that fixed sampling time of CALIOP can result in underestimation of cirrus clouds above the tropopause. Most of the time, the mid-cloud temperature is less than $-65^{\circ} \mathrm{C}$ and found to be as low as $-85^{\circ} \mathrm{C}$ (Fig. 4e). NARL lidar and CALIOP night-time data in Fig. $4 \mathrm{f}$ show that nearly $50-55 \%$ of cirrus clouds observed over Gadanki have a thickness less than $2 \mathrm{~km}$. Though, we observed significant day-night differences in the occurrence of cirrus clouds, the day and night distribution of macrophysical and thermodynamic properties of cirrus clouds do not differ much.

The geometrical thickness of cirrus clouds depends on the formation mechanism, cloud altitude and cloud-temperature. Figure $5 \mathrm{a}-\mathrm{c}$ show the dependence of geometrical thickness on the base altitude of the cloud $\left(z_{\mathrm{b}}\right)$. For this, we divided all the cirrus cloud layers into three groups based on their occurrence in the different altitude regions. These altitude regions are $8 \mathrm{~km}<z_{\mathrm{b}}<12 \mathrm{~km}, 12 \mathrm{~km}<z_{\mathrm{b}}<15 \mathrm{~km}$ and $z_{\mathrm{b}}>15 \mathrm{~km}$. Clouds of thickness less than $2 \mathrm{~km}$ occur predom- 

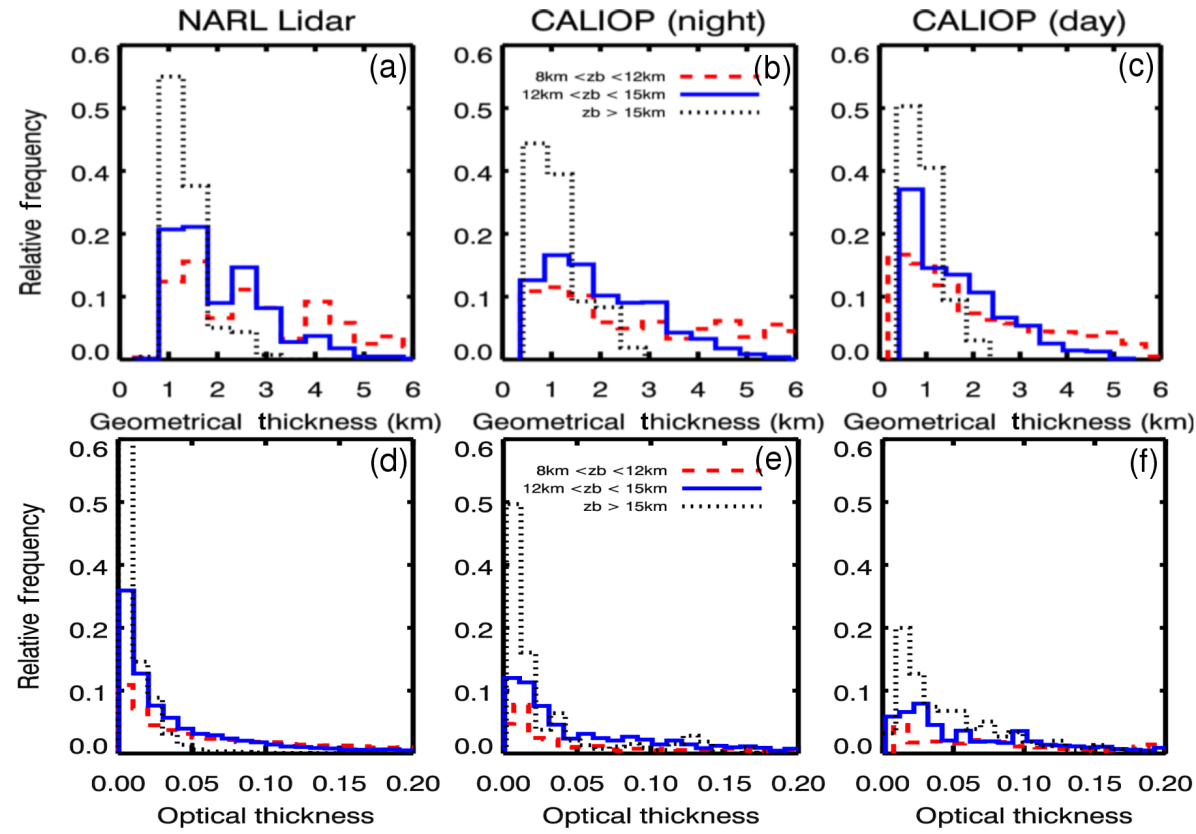

Figure 5. Histograms showing the frequency distribution of geometrical thickness (a-c) and optical thickness (d-f) of cirrus cloud layers with base height $\left(z_{\mathrm{b}}\right)$ in the ranges of $8 \mathrm{~km}<z_{\mathrm{b}}<12 \mathrm{~km}$ (dashed red line), $12 \mathrm{~km}<z_{\mathrm{b}}<15 \mathrm{~km}$ (solid blue line) and $z_{\mathrm{b}}>15 \mathrm{~km}$ (dotted black line) obtained from NARL Lidar data (a and d) for the period 1998-2013, CALIOP night-time data (b and e) and CALIOP daytime (c and f) data sets for the period 2006-2013. Bin size for each histogram of geometrical thickness is $0.5 \mathrm{~km}$ while for optical thickness it is 0.01 .

inantly in altitude range above $15 \mathrm{~km}$. Our results agree well with the results obtained using ground-based lidars at other tropical stations viz. Nauru Island (Comstock et al., 2002) and Maldives (Seifert et al., 2007). However, NARL lidar is found to have a larger number of thin clouds in the altitude range above $15 \mathrm{~km}$ than CALIOP during night-time. Again the comparison of NARL lidar and CALIOP daytime for clouds above $15 \mathrm{~km}$ is good, although caution is advised by Thorsen et al. (2013) while interpreting the daytime cirrus cloud observation using CALIOP which are biased towards the smaller geometrical thicknesses. Optical properties of these clouds are discussed in the next sub-section.

\subsection{Optical properties of cirrus clouds}

The distributions of optical thickness of cirrus clouds observed over Gadanki using NARL lidar and CALIOP data sets are shown in Fig. 6a. The optical thickness of cirrus cloud layers is binned into intervals of 0.1 . We see a high fraction of cirrus clouds with optical thickness less than 0.1 in all three data sets. To further investigate the distribution of optical thickness we divide each data set of cirrus clouds into different categories. Based on the magnitude of optical thickness, Sassen and Cho (1992) classified cirrus clouds into three categories viz. sub-visible cirrus clouds whose optical thickness, $\tau_{\text {cloud }}<0.03$; thin cirrus clouds with $0.03<\tau_{\text {cloud }}<0.3$ and thick cirrus clouds with $\tau_{\text {cloud }}>0.3$. When this classification was applied to NARL lidar data set, we find that sub-visible, thin and thick cirrus clouds occurred nearly 52\% (56\% during 2006-2013), 36\% (36\% during 2006-2013) and $11 \%$ (8\% during 2006-2013) of the total observation time, respectively. Sunil Kumar et al. (2003) have also reported the similar high occurrence of sub-visible cirrus using 6 years of data over Gadanki. In contrast, nearly equal occurrence of the three cloud categories i.e. $35 \%$ subvisible, $32 \%$ thin and $33 \%$ thick cirrus clouds is observed in CALIOP data, possibly due to inability of CALIOP to detect sub-visible cirrus clouds. It is worth mentioning that the aircraft studies made during Tropical Composition, Clouds, and Climate Coupling (TC4) experiment which revealed that more than $50 \%$ of sub-visible cirrus cloud with thicknesses less than 0.01 are unaccounted in the current CALIOP level 2 cloud products (Davis et al., 2010). Martins et al. (2011) also have reported the underestimation of sub-visible cirrus clouds fraction in CALIOP level 2 cloud data products. Frequency distributions for the individual categories are shown in Fig. 6b-d. CALIOP (day) data set shows very few cases of sub-visible cirrus clouds with optical depth less than 0.007 (Fig. 6b) whereas night-time observations from NARL lidar and CALIOP show high occurrence of cirrus clouds with optical thickness less than 0.007. This can be explained by the low sensitivity of CALIOP to the daytime cirrus clouds due to the higher background noise than that during night-time. Overall, the distributions of optical thicknesses of cirrus clouds show good agreement between NARL lidar and CALIOP data sets. These distributions are also in good agreement with the findings of Comstock et al. (2002). 

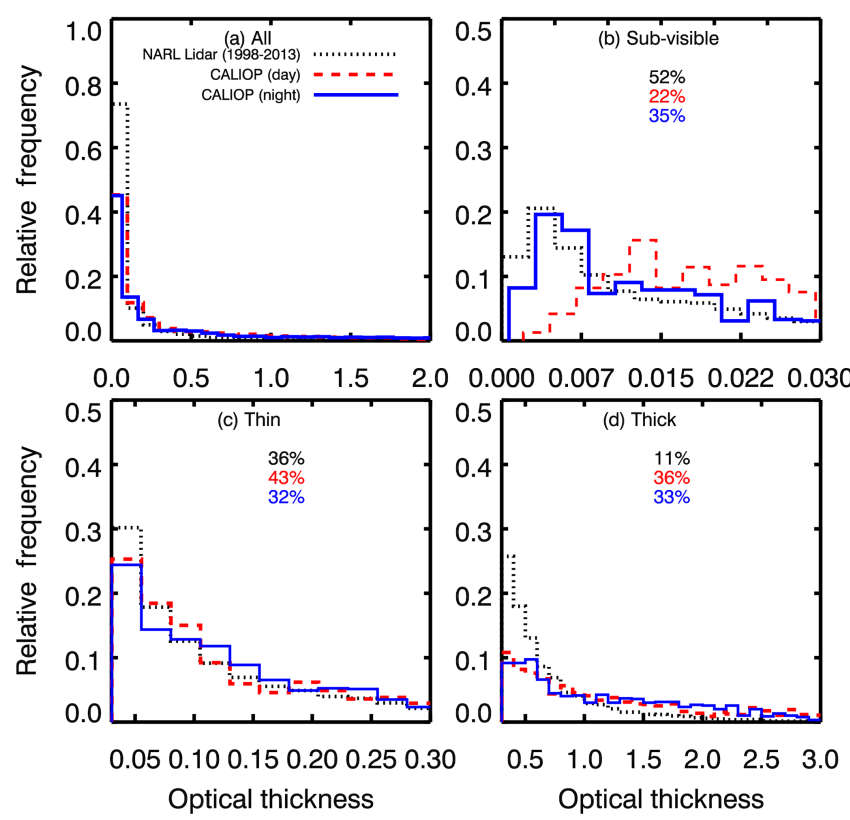

Figure 6. Histograms showing the frequency distribution of optical thickness of (a) all cirrus cloud layers (bin-size $=0.1$ ), (b) sub-visible cirrus $(\tau<0.03$, bin-size $=0.0025)$, (c) thin cirrus $(0.03<\tau<0.3$, bin-size $=0.025)$ and $(\mathbf{d})$ thick cirrus cloud layers $(\tau>0.3$, bin-size $=0.1)$ obtained from NARL Lidar (dotted black line), CALIOP daytime (dashed red line) and CALIOP night-time (solid blue line) data sets. Percentage mentioned in each panel is in the same order as legend in (a).

Figure 6d reveals that NARL lidar sampled smaller number of thick cirrus clouds with $\tau_{\text {cloud }}>1.5$ as compared to CALIOP. This is possibly due to the lack of NARL lidar observations on cloudy nights and lidar's inability to penetrate the opaque clouds.

The optical thickness of cirrus clouds depends on the formation mechanism, cloud altitude, cloud temperature, amount, size, shape and orientation of ice-crystals. To investigate the dependence of cirrus optical properties on altitude, we categorized cirrus cloud optical thickness obtained from each data set into three different classes based on their base altitude in the same way we did for the geometrical thickness in Sect. 4.3 (Fig. 5). Each data set confirms the high occurrence of sub-visible cirrus clouds occurring above $15 \mathrm{~km}$ (Fig. 5d-f). In addition to this, we find that the fraction of sub-visible cirrus clouds detected by NARL lidar is higher than that detected by CALIOP.

The distribution of each cirrus cloud type as a function of the mid-cloud altitude is depicted in Fig. 7. We observe that the distribution of sub-visible cirrus clouds from each of the data sets is skewed towards the tropopause (between 16 and $17 \mathrm{~km}$ ). Most of the sub-visible cirrus clouds (Fig. 7b) have their mid-cloud altitude in between 14 and $17 \mathrm{~km}$ with maxima at around $16 \mathrm{~km}$. The distribution of thin cirrus clouds is also similar to the sub-visible cirrus clouds in case of
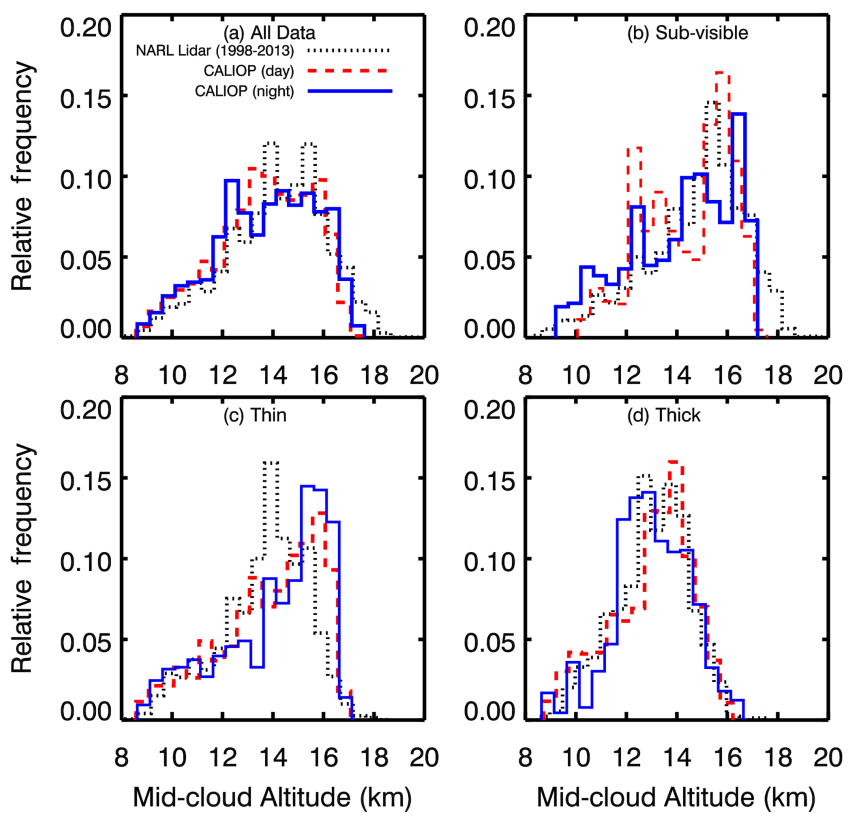

Figure 7. Histograms showing the frequency distribution of midcloud altitude in bins of $0.5 \mathrm{~km}$ for (a) all cirrus cloud layers, (b) sub-visible cirrus $(\tau<0.03)$, (c) thin cirrus $(0.03<\tau<0.3)$ and (d) thick cirrus cloud layers $(\tau>0.3)$ obtained from NARL Lidar (dotted black line), CALIOP daytime (dashed red line) and CALIOP night-time (solid blue line) data sets.

CALIOP data set but the NARL lidar has a peak in the frequency distribution at lower altitude $(14 \mathrm{~km})$ (Fig. 7c). Thick cirrus clouds as shown in Fig. $7 \mathrm{~d}$ occur most of the time in the altitude range of $12-14 \mathrm{~km}$ which may be of convective origin.

Distribution of geometrical thickness with a bin size of $0.5 \mathrm{~km}$ for each cirrus cloud type and for each data set is shown in Fig. 8. Most of the sub-visible cirrus clouds are less than $2 \mathrm{~km}$ thick (Fig. 8b). CALIOP daytime data show the high fraction of sub-visible cirrus clouds in the $0-0.5 \mathrm{~km}$ bin. The distribution of geometrical thickness for thin clouds obtained from NARL lidar slightly differs from that of CALIOP as shown in Fig. 8c. In case of the NARL lidar, the peak of the frequency distribution is at about $2.5 \mathrm{~km}$ thickness, whereas in the case of CALIOP the peak of the frequency distribution is less than $2 \mathrm{~km}$. The geometrical thickness of the majority of thin cirrus clouds is less than $3 \mathrm{~km}$. The flat distribution of geometrical thickness for thick cirrus clouds shown in Fig. 8d indicates the diversity in the thickness of cirrus clouds. Night-time distributions from both lidars agree well for thick clouds. However, the bias of CALIOP daytime observations towards smaller geometrical thicknesses can be seen clearly from Fig. $8 \mathrm{~d}$. This can be explained by the presence of high solar background noise in the CALIOP daytime observations (Thorsen et al., 2013). The detection of true boundaries of cirrus clouds becomes cumbersome in the presence of high background noise especially when there 

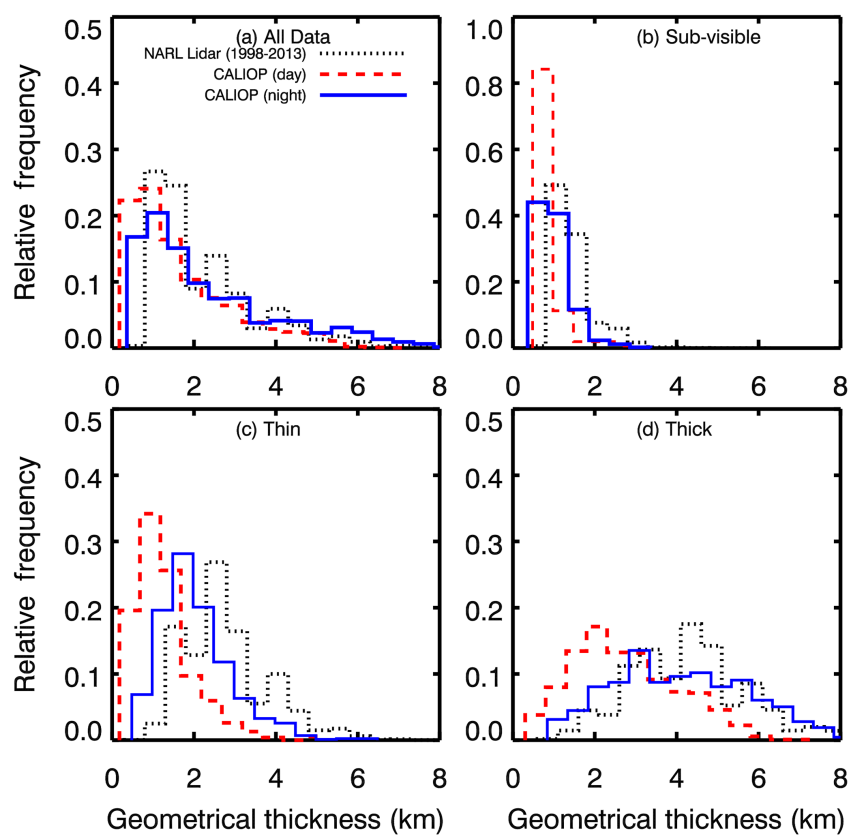

Figure 8. Histograms showing the frequency distribution of geometrical thickness in bins of $0.5 \mathrm{~km}$ for (a) all cirrus cloud layers, (b) sub-visible cirrus $(\tau<0.03)$, (c) thin cirrus $(0.03<\tau<0.3)$ and (d) thick cirrus cloud layers $(\tau>0.3)$ obtained from NARL Lidar (dotted black line), CALIOP daytime (dashed red line) and CALIOP night-time (solid blue line) data sets.

are thick clouds below the cirrus clouds. The $60 \mathrm{~m}$ vertical resolution of CALIOP could also be one of the reasons behind the high frequency of clouds in the initial bins (smaller values) of geometrical thickness.

\subsection{Temperature dependence of cirrus properties}

In the previous section it is shown that the geometrical thickness of cirrus clouds has altitude dependence. We also found that most of the cirrus clouds occurring above $15 \mathrm{~km}$ have a geometrical thickness less than $2 \mathrm{~km}$ while clouds below $15 \mathrm{~km}$ showed the broader distribution (Fig. 5a-c). We investigate the dependence of geometrical and optical properties of cirrus clouds on temperature in this section. Note that the mid-cloud temperature used in the case of NARL lidar data set is NCEP FNL data whereas in case of CALIOP data set it is GMAO temperature profile data. Figure 9a shows the dependence of geometrical thickness of cirrus clouds on the mid-cloud temperature. The geometrical thickness increases from 1 to $3.5 \mathrm{~km}$ as mid-cloud temperature increases from -90 to $-60^{\circ} \mathrm{C}$. For the further increase in temperature from -60 to $-20^{\circ} \mathrm{C}$, the geometrical thickness decreases to less than $1 \mathrm{~km}$. A very nice agreement is observed between CALIOP night-time and NARL lidar data. The geometrical thickness of cirrus clouds exhibits large variation of about $1-5 \mathrm{~km}$ in the mid-cloud temperature range of -50 to $-70^{\circ} \mathrm{C}$ with a mean geometrical thickness greater than $2 \mathrm{~km}$.

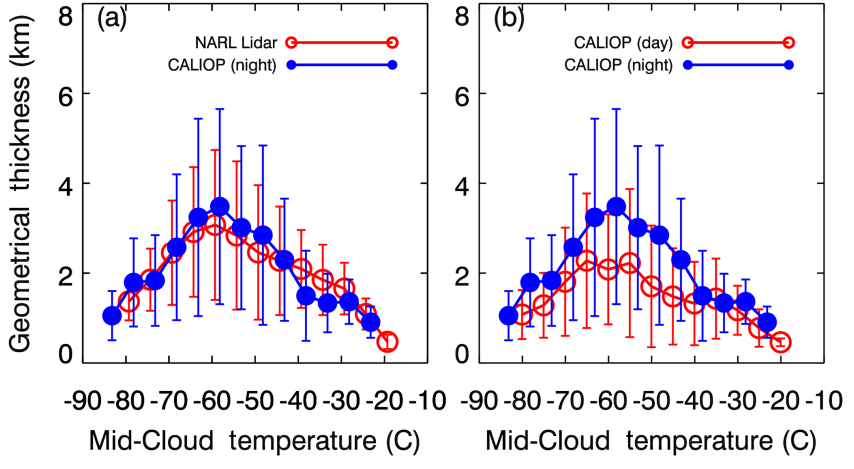

Figure 9. Dependence of geometrical thickness of cirrus cloud layers on mid-cloud temperature obtained from (a) NARL Lidar (open red circles) and CALIOP night-time (filled blue circles) data, (b) CALIOP daytime (open red circles) and CALIOP night-time (filled blue circles) data. Circles show the average value while the error bars show the standard deviation.

This is in contrast to Sunilkumar and Parameswaran (2005) who found it to be about $1.7 \mathrm{~km}$ over Gadanki. This could be possibly due to the use of temperature profiles based on MST Radar by Sunilkumar and Parameswaran (2005), which are not as accurate as NCEP FNL data and have lower values compared to CIRA Model temperature profile (Parameswaran et al., 2000). However, difference in temperature profile alone is not sufficient to explain the difference in cloud thickness. Also, the other factors like length of data set and differences in cloud detection algorithms may have contributed to the observed difference noticed in the two studies. The dependence of geometrical thickness on mid-cloud temperature obtained from CALIOP night-time data is compared with that obtained from CALIOP daytime data and is shown in Fig. 9b. In the temperature range of -45 to $-60^{\circ} \mathrm{C}$, the daytime dependence appears to be weaker than the nighttime dependence. This could be due to underestimation of geometrical thickness of clouds during daytime by CALIOP as discussed in previous section.

It is important to know the temperature ranges at which optically different cloud types exist. Figure 10 shows the distribution of mid-cloud temperature for each cirrus types. Both, night-time data sets show that the majority of sub-visible cirrus clouds occur at temperatures lower than $-65^{\circ} \mathrm{C}$ (Fig. 10b). In the temperature range of -60 to $-80^{\circ} \mathrm{C}$, most of the thin cirrus clouds occur (Fig. 10c). The distributions of sub-visible and thin cirrus clouds are skewed towards very low temperature. While most of the thick cirrus clouds occur in the temperature range of -40 to $-70^{\circ} \mathrm{C}$. The type of cirrus clouds is found to be dependent on different temperature regimes. This may be mainly due to the differences in the cloud-formation mechanisms for example sub-visible cirrus are formed due to in situ generation near tropopause height whereas thick cirrus are generally formed by convec- 

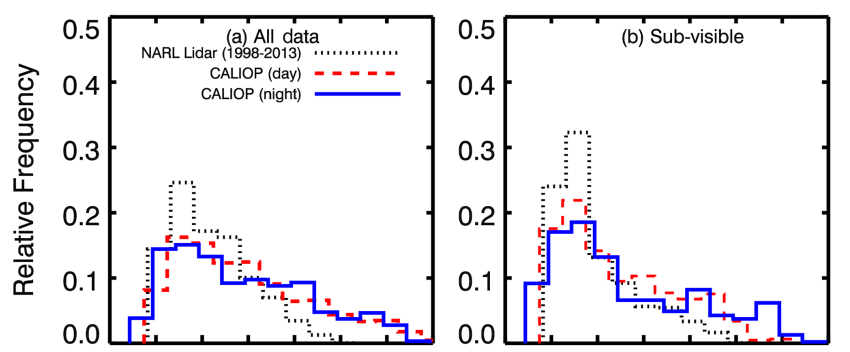

$-90-80-70-60-50-40-30-20 \quad-90-80-70-60-50-40-30-20$

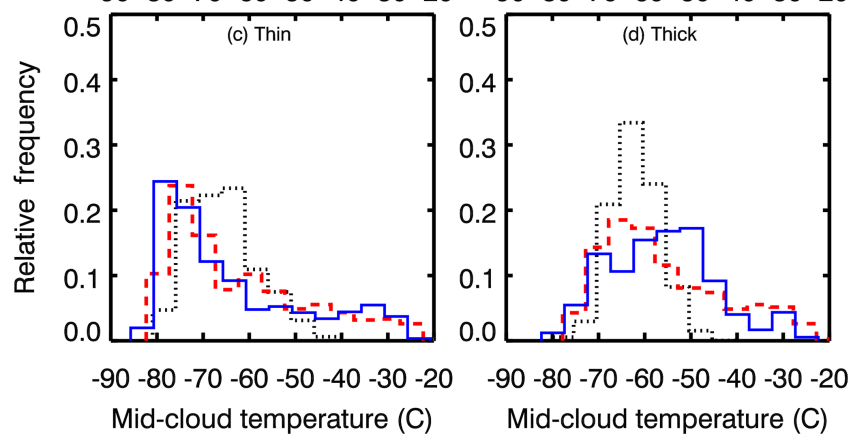

Figure 10. Histograms showing the frequency distribution of midcloud temperature in bins of $5^{\circ} \mathrm{C}$ for (a) all cirrus cloud layers, (b) sub-visible cirrus $(\tau<0.03)$, (c) thin cirrus $(0.03<\tau<0.3)$ and (d) thick cirrus cloud layers $(\tau>0.3)$ obtained from NARL Lidar (dotted black line), CALIOP daytime (dashed red line) and CALIOP night-time (solid blue line) data sets.

tive outflow at relatively lower heights except during deep overshooting convections.

\subsection{Long-term trends}

As mentioned in the introduction of this manuscript that the ingredients needed for cirrus cloud formation are changing in the present climate change scenario, here in this section we have made an attempt to see whether these changes have affected cirrus cloud properties or not. In our earlier study (Pandit et al., 2014), we reported an $8.4 \%$ increase in percentage occurrence of cirrus clouds at $16 \mathrm{~km}$ altitude and 0.41 and $0.56 \mathrm{~km}$ increase in cloud base and top heights, respectively, over Gadanki in 16 years. However, the percentage increase of $8.4 \%$ was not statistically significant. These findings strengthen the hypothesis that warming climate will cause an upward shift of cirrus cloud (Boucher et al., 2013; Hartmann and Larson, 2002). Assuming a simple linear temporal relation, the rate of upward shift of the base altitude is found to be about $26 \mathrm{~m}_{\text {year }}{ }^{-1}$ while that of the top altitude is found to be about $35 \mathrm{~m}_{\text {year }}{ }^{-1}$. Chepfer et al. (2014) have predicted an upward shift in the cirrus cloud altitude in tropics at a typical rate of $20 \mathrm{~m}_{\text {year }}{ }^{-1}$ using multiple climate models. Using 6 years of CALIOP observations, Zhou et al. (2014) have also showed an increase in the amount and altitude of cirrus clouds in response to the surface warming. Since the trends presented in Pandit et al. (2014) were not separated for cloud types (i.e. sub-visible, thin and thick cirrus clouds) and were presented only for three properties (viz. cloud-base-altitude, cloud-top-altitude and percentage occurrence), therefore, here we investigate long-term trends in mid-cloud altitude, mid-cloud temperature, geometrical thickness and optical thickness of each of these cirrus cloud type using both lidars. Figure 11 shows the trends in abovementioned properties of sub-visible cirrus clouds. Trends in these properties for all three cirrus cloud types are provided in Table S2. In the last 16 years, the monthly mean midcloud altitude of sub-visible cirrus clouds is found to be increasing at the rate of $41 \pm 21 \mathrm{~m}$ year $^{-1}$. The trend is found to be statistically significant ( $p$ values 0.05 using Student $t$ test). CALIOP observations also show an increasing trend in the mid-altitude but was found to be statistically insignificant. As expected from mid-cloud-altitude trend, both lidars show that the mid-cloud temperature is decreasing, which is found to be statistically insignificant. The geometrical thickness however, does not show a statistically significant trend in any of the lidar observations over Gadanki. This is in contrast to mid-latitude station OHP, France where Hoareau et al. (2013) found a statistically significant increase in geometrical thickness but an insignificant trend in cloud-midaltitude. The optical thickness of sub-visible cirrus clouds obtained from both lidars is found to be decreasing. The trend $-9.4 \times 10^{-5} \pm 5.5 \times 10^{-5}$ per year in the optical thickness of sub-visible cirrus clouds obtained from NARL Lidar is statistically significant ( $p$ value 0.09 ) while CALIOP trend is statistically insignificant. All the properties were found to have statistically insignificant trends for thin and thick cirrus clouds except for one. Thick cirrus cloud shows statistically significant decreasing trend ( $p$ value 0.01 ) of $-1.5 \times 10^{-2} \pm 5.3 \times 10^{-3}$ per year in cloud optical thickness (Fig. S1 in the Supplement). In the latest IPCC report (Boucher et al., 2013), a systematic shift from thick high clouds to thin cirrus clouds or vice-versa is suggested as a possible mechanism for cloud-climate feedback, however, at the time of writing the IPCC report, evidence for such systematic shift was not available. In this context, we have investigated trends in the fraction of three cloud types. The fraction of sub-visible cloud type is found to have statistically significant ( $p$ value 0.1 ) increase of $9.4 \%$ over 16 years. The increase is at the cost of decrease in thin cirrus cloud fraction which is decreased by $7.6 \%$. It is worth quoting the future projections of the Coupled Model Inter-Comparison Project Phase 5 (CMIP5) which are presented from 2006-2099 under the Representative Concentration Pathway (RCP) 8.5 scenarios. The projection shows warming trend at $100 \mathrm{hPa}$ over wide region of $60^{\circ} \mathrm{N}-45^{\circ} \mathrm{S}$ by the end of twenty-first century (Kishore et al., 2015). The projected increase in temperature of $\sim 3.27 \mathrm{~K}$ at the end of the twenty-first century at $100 \mathrm{hPa}$ is partly attributed to the increase of sub-visible cirrus clouds near the tropopause region. These may also have significant implications for cross-tropopause water vapour transport and related global climate variability. 

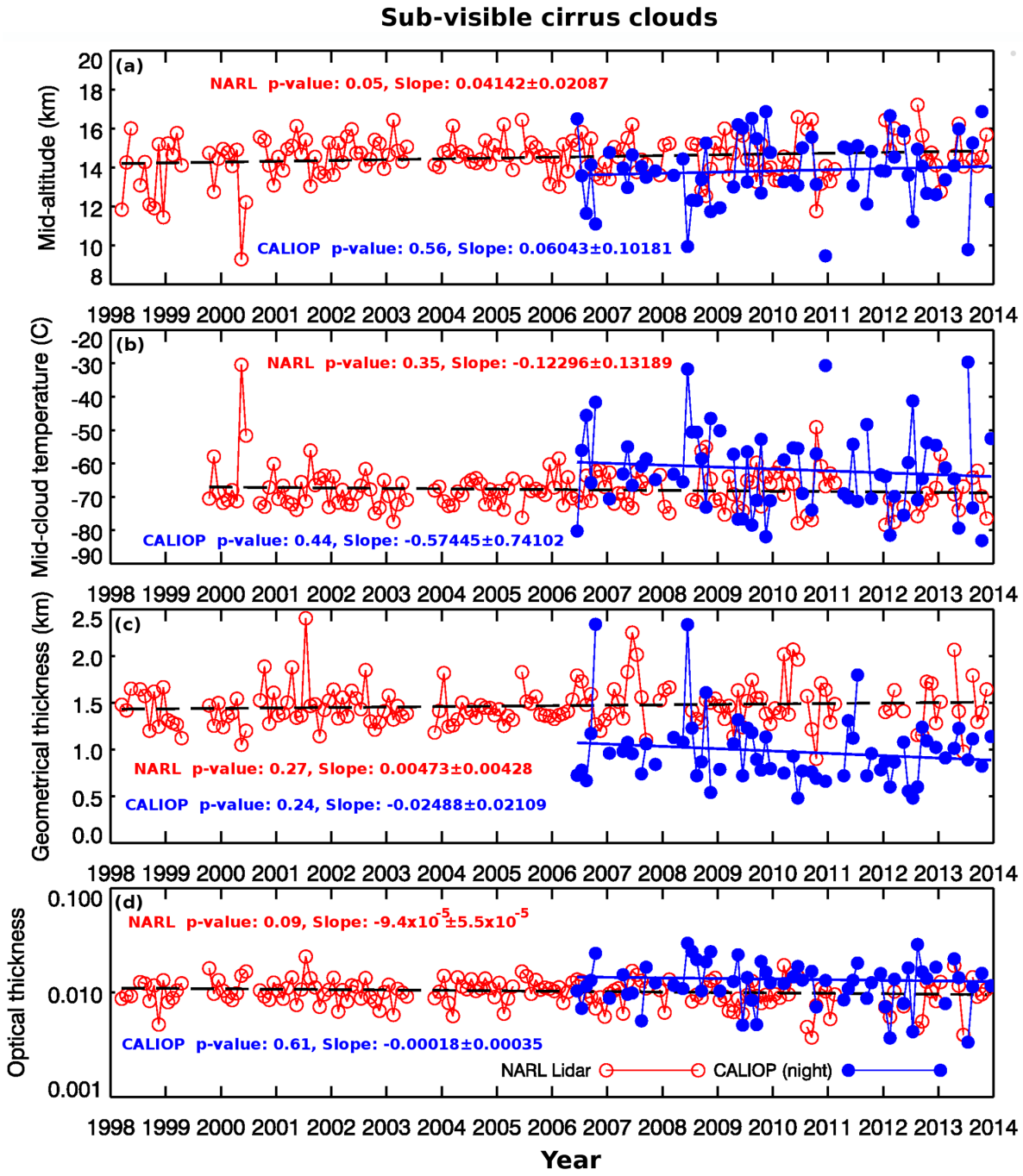

Figure 11. Time series of monthly mean (a) mid-cloud altitude, (b) mid-cloud temperature, (c) geometrical thickness and (d) optical thickness of sub-visible cirrus clouds obtained using NARL Lidar (shown by open red circles) and CALIOP night time data (shown by blue filled circle). The dashed black line shows the linear fit to the NARL Lidar data points while the solid blue line shows the same for CALIOP data points. Slopes are expressed in unit per year.

\section{Summary and conclusions}

Using the 16 years of lidar observations from a tropical rural site, climatology of cirrus cloud properties is developed and long-term trends are analysed. The ground-based climatology is also compared with the 7 and a half year climatology of cirrus clouds observed using CALIOP. Both data sets exhibit good agreement with each other. Some of the salient features of cirrus clouds emerged from this climatology are summarized below:

1. During the months of May to September, a significant percentage of cirrus clouds are found to occur near the climatological tropopause, while $9 \%$ of them are found above the tropopause.
2. About $50-55 \%$ of the cirrus clouds observed over Gadanki have a geometrical thickness less than $2 \mathrm{~km}$.

3. Cirrus clouds that occurred with mid-cloud temperature between -50 to $-70^{\circ} \mathrm{C}$ have a mean geometrical thickness greater than $2 \mathrm{~km}$ in contrast to the value $1.7 \mathrm{~km}$ reported by Sunilkumar and Parameswaran (2005). Most of the sub-visible and thin cirrus clouds occurred with a mid-cloud temperature less than $-60^{\circ} \mathrm{C}$.

4. Analyses of long-term trends show the following: (a) Among the three types only the sub-visible cirrus clouds show an increase in their altitude of occurrence. (b) Optical thickness of sub-visible and thick cirrus clouds shows a statistically significant decreasing trend. (c) A $9.4 \%$ increase in sub-visible cirrus cloud frac- 
tion and $7.6 \%$ decrease in thin cirrus cloud fraction are found from year 1998 to 2013.

5. The climatology of the NARL lidar and the CALIOP data shows that the NARL lidar detects a higher number of sub-visible cirrus clouds ( $56 \%$ of the total observations) compared to CALIOP (35\% of the total observations) for the overlapping period. This has implications in global warming studies as sub-visible cirrus clouds have significant positive radiative forcing and their underestimation will lead to underestimation of the role of cirrus clouds in global warming.

\section{The Supplement related to this article is available online at doi:10.5194/acp-15-13833-2015-supplement.}

Acknowledgements. We thank all colleagues associated with the operation and maintenance of NARL lidar at Gadanki since 1998. We also thank NARL data centre for providing lidar data. We acknowledge the assistance given by NASA Langley Research Centre and UCAR in providing CALIPSO and NCEP FNL data, respectively. One of the authors (Amit Kumar Pandit) thanks Department of Space, Government of India for providing research fellowship to carry out this research.

Edited by: M. Krämer

\section{References}

Boucher, O., Randall, D., Artaxo, P., Bretherton, C., Feingold, G., Forster, P., Kerminen, V.-M., Kondo, Y., Liao, H., Lohmann, U., Rasch, P., Satheesh, S. K., Sherwood, S., Stevens, B., and Zhang, X.-Y.: Clouds and Aerosols, in: Climate Change 2013: The Physical Science Basis. Contribution of Working Group I to the Fifth Assessment Report of the Intergovernmental Panel on Climate Change, edited by: Stocker, T. F., Qin, D., Plattner, G.-K., Tignor, M., Allen, S. K., Boschung, J., Nauels, A., Xia, Y., Bex, V., Midgley, P. M., Cambridge University Press, Cambridge, United Kingdom and New York, NY, USA, 571-658, doi:10.1017/CBO9781107415324.016, 2013.

Chen, T., Rossow, W. B., and Zhang, Y.: Radiative Effects of Cloud-Type Variations, J. Clim., 13, 264-286, doi:10.1175/15200442(2000)013<0264:REOCTV>2.0.CO;2, 2000.

Chen, W.-N., Chiang, C.-W., and Nee, J.-B.: Lidar ratio and depolarization ratio for cirrus clouds, Appl. Opt., 41, 6470-6476, doi:10.1364/ao.41.006470, 2002.

Chepfer, H., Pelon, J., Brogniez, G., Flamant, C., Trouillet, V., and Flamant, P. H.: Impact of cirrus cloud ice crystal shape and size on multiple scattering effects: Application to spaceborne and airborne backscatter lidar measurements during LITE Mission and E LITE Campaign, Geophys. Res. Lett., 26, 2203-2206, doi:10.1029/1999GL900474, 1999.
Chepfer, H., Noel, V., Winker, D., and Chiriaco, M.: Where and when will we observe cloud changes due to climate warming?, Geophys. Res. Lett., 41, 2014GL061792, doi:10.1002/2014GL061792, 2014.

Comstock, J. M., Ackerman, T. P., and Mace, G. G.: Ground-based lidar and radar remote sensing of tropical cirrus clouds at Nauru Island: Cloud statistics and radiative impacts, J. Geophys. Res.Atmos., 107, 4714, doi:10.1029/2002JD002203, 2002.

Davis, S., Hlavkaet, D., Jensen, E., Rosenlof, K., Yang, Q., Schmidt, S., Borrmann, S., Frey, W., Lawson, P., Voemel, H., and Bui, T. P.: In situ and lidar observations of tropopause subvisible cirrus clouds during TC4, J. Geophys. Res., 115, D00J17, doi:10.1029/2009JD013093, 2010.

Eloranta, E.: Practical model for the calculation of multiply scattered lidar returns, Appl. Opt., 37, 2464-2472, doi:10.1364/ao.37.002464, 1998.

Hartmann, D. L., Ockert-Bell, M. E., and Michelsen, M. L.: The Effect of Cloud Type on Earth's Energy Balance: Global Analysis, J. Clim., 5, 1281-1304, doi:10.1175/1520-0442(1992)005< 1281:TEOCTO>2.0.CO;2, 1992.

Hartmann, D. L. and Larson, K.: An important constraint on tropical cloud - climate feedback, Geophys. Res. Lett., 29, 1951, doi:10.1029/2002GL015835, 2002.

Hoareau, C., Keckhut, P., Noel, V., Chepfer, H., and Baray, J.L.: A decadal cirrus clouds climatology from ground-based and spaceborne lidars above the south of France $\left(43.9^{\circ} \mathrm{N}-5.7^{\circ} \mathrm{E}\right)$, Atmos. Chem. Phys., 13, 6951-6963, doi:10.5194/acp-13-69512013, 2013.

Hogan, R. J.: Fast approximate calculation of multiply scattered lidar returns, Appl. Opt., 45, 5984, doi:10.1364/AO.45.005984, 2006.

Hunt, W. H., Winker, D. M., Vaughan, M. A., Powell, K. A., Lucker, P. L., and Weimer, C.: CALIPSO lidar description and performance assessment, J. Atmospheric Ocean. Technol., 26, 12141228, doi:10.1175/2009JTECHA1223.1, 2009.

Kaestner, M.: Lidar inversion with variable backscatter/extinction ratios: comment, Appl. Opt., 25, 833-835, doi:10.1364/ao.25.000833, 1986.

Kishore, P., Basha, G., Venkat Ratnam, M., Velicogna, I., Ouarda, T. B. M. J, and Narayana Rao, D.: Evaluating CMIP5 models using GPS Radio Occultation COSMIC temperature in UTLS region during 2006-2013: 21st century projection and trends, Clim. Dynamics, revised, 2015.

Kulkarni, P., Ramachandran, S., Bhavani Kumar, Y., Narayana Rao, D., and Krishnaiah, M.: Features of upper troposphere and lower stratosphere aerosols observed by lidar over Gadanki, a tropical Indian station, J. Geophys. Res.-Atmos., 113, D17207, doi:10.1029/2007JD009411, 2008.

Liou, K.-N.: Influence of Cirrus Clouds on Weather and Climate Processes: A Global Perspective, Mon. Weather Rev., 114, doi:10.1175/1520-0493(1986)114<1167:IOCCOW>2.0.CO;2, 1986.

Liou, K. N.: Cirrus clouds and climate in McGraw-Hill Yearbook of Science and Technology, Columbus, Ohio, USA, 432 pp., 2005.

Liu, C. and Zipser, E. J.: Diurnal cycles of precipitation, clouds, and lightning in the tropics from 9 years of TRMM observations, Geophys. Res. Lett., 35, L04819, doi:10.1029/2007GL032437, 2008. 
Lynch, D. K., Sassen, K., Starr, D., and Stephens, G. (Eds.): Cirrus, Oxford University Press, New York, USA, 499 pp., 2002.

Martins, E., Noel, V., and Chepfer, H.: Properties of cirrus and subvisible cirrus from nighttime Cloud-Aerosol Lidar with Orthogonal Polarization (CALIOP), related to atmospheric dynamics and water vapor, J. Geophys. Res.-Atmos., 116, D02208, doi:10.1029/2010JD014519, 2011.

Massie, S. T., Khosravi, R., and Gille, J. C.: A multidecadal study of cirrus in the tropical tropopause layer, J. Geophys. Res.-Atmos., 118, 7938-7947, doi:10.1002/jgrd.50596, 2013.

Nazaryan, H., McCormick, M. P., and Menzel, W. P.: Global characterization of cirrus clouds using CALIPSO data, J. Geophys. Res.-Atmos., 113, D16211, doi:10.1029/2007JD009481, 2008.

Pandit, A. K., Gadhavi, H., Ratnam, M. V., Jayaraman, A., Raghunath, K., and Rao, S. V. B.: Characteristics of cirrus clouds and tropical tropopause layer: Seasonal variation and long-term trends, J. Atmos. Sol.-Terr. Phys., 121, 248-256, doi:10.1016/j.jastp.2014.07.008, 2014.

Pan, L. L. and Munchak, L. A.: Relationship of cloud top to the tropopause and jet structure from CALIPSO data, J. Geophys. Res.-Atmos., 116, D12201, doi:10.1029/2010JD015462, 2011.

Parameswaran, K., Sasi, M., Ramkumar, G., Nair, P. R., Deepa, V., Murthy, B., Nayar, S., Revathy, K., Mrudula, G., Satheesan, K., Bhavanikumar, Y., Sivakumar, V., Raghunath, K., Rajendraprasad, T., and Krishnaiah, M.: Altitude profiles of temperature from 4 to $80 \mathrm{~km}$ over the tropics from MST radar and lidar, J. Atmos. Sol.-Terr. Phys., 62, 1327-1337, doi:10.1016/s13646826(00)00124-3, 2000.

Randel, W. J. and Jensen, E. J.: Physical processes in the tropical tropopause layer and their roles in a changing climate, Nat. Geosci, 6, 169-176, doi:10.1038/ngeo1733, 2013.

Rosenlof, K. H., Oltmans, S. J., Kley, D., Russell, J. M., Chiou, E.-W., Chu, W. P., Johnson, D. G., Kelly, K. K., Michelsen, H. A., Nedoluha, G. E., Remsberg, E. E., Toon, G. C., and McCormick, M. P.: Stratospheric water vapor increases over the past half-century, Geophys. Res. Lett., 28, 1195-1198, doi:10.1029/2000GL012502, 2001.

Sassen, K. and Cho, B. S.: Subvisual-Thin cirrus lidar dataset for satellite verification and climatological research, J. Appl. Meteorol., 31, 1275-1285, doi:10.1175/15200450(1992)031<1275:STCLDF>2.0.CO;2, 1992.

Sassen, K. and Comstock, J. M.: A Midlatitude Cirrus Cloud Climatology from the Facility for Atmospheric Remote Sensing. Part III: Radiative Properties, J. Atmospheric Sci., 58, 2113-2127, doi:10.1175/1520-0469(2001)058<2113:AMCCCF>2.0.CO;2, 2001.

Sassen, K., Wang, Z., and Liu, D.: Cirrus clouds and deep convection in the tropics: Insights from CALIPSO and CloudSat, J. Geophys. Res.-Atmos., 114, D00H06, doi:10.1029/2009JD011916, 2009.

Seifert, P., Ansmann, A., Müller, D., Wandinger, U., Althausen, D., Heymsfield, A. J., Massie, S. T., and Schmitt, C.: Cirrus optical properties observed with lidar, radiosonde, and satellite over the tropical Indian Ocean during the aerosol-polluted northeast and clean maritime southwest monsoon, J. Geophys. Res.-Atmos., 112, D17205, doi:10.1029/2006JD008352, 2007.

Solomon, S., Rosenlof, K. H., Portmann, R. W., Daniel, J. S., Davis, S. M., Sanford, T. J., and Plattner, G.-K.: Contributions of Strato- spheric Water Vapor to Decadal Changes in the Rate of Global Warming, Science, 327, 1219-1223, 2010.

Stephens, G. L., Wood, N. B., and Gabriel, P. M.: An Assessment of the Parameterization of Subgrid-Scale Cloud Effects on Radiative Transfer. Part I: Vertical Overlap, J. Atmospheric Sci., 61, 715-732, doi:10.1175/15200469(2004)061<0715:AAOTPO>2.0.CO;2, 2004.

Stubenrauch, C. J., Cros, S., Guignard, A., and Lamquin, N.: A 6-year global cloud climatology from the Atmospheric InfraRed Sounder AIRS and a statistical analysis in synergy with CALIPSO and CloudSat, Atmos. Chem. Phys., 10, 7197-7214, doi:10.5194/acp-10-7197-2010, 2010.

Stubenrauch, C. J., Rossow, W. B., Kinne, S., Ackerman, S., Cesana, G., Chepfer, H., Di Girolamo, L., Getzewich, B., Guignard, A., Heidinger, A., Maddux, B. C., Menzel, W. P., Minnis, P., Pearl, C., Platnick, S., Poulsen, C., Riedi, J., Sun-Mack, S., Walther, A., Winker, D., Zeng, S., and Zhao, G.: Assessment of Global Cloud Datasets from Satellites: Project and Database Initiated by the GEWEX Radiation Panel, Bull. Am. Meteorol. Soc., 94, 1031-1049, doi:10.1175/BAMS-D-12-00117.1, 2013.

Sunil Kumar, S. V., Parameswaran, K., and Krishna Murthy, B. V.: Lidar observations of cirrus cloud near the tropical tropopause: general features, Atmospheric Res., 66, 203-227, doi:10.1016/S0169-8095(02)00159-X, 2003.

Sunilkumar, S. V. and Parameswaran, K.: Temperature dependence of tropical cirrus properties and radiative effects, J. Geophys. Res.-Atmos., 110, D13205, doi:10.1029/2004JD005426, 2005.

Thorsen, T. J., Fu, Q., Comstock, J. M., Sivaraman, C., Vaughan, M. A., Winker, D. M., and Turner, D. D.: Macrophysical properties of tropical cirrus clouds from the CALIPSO satellite and from ground-based micropulse and Raman lidars, J. Geophys. Res.Atmos., 118, 9209-9220, doi:10.1002/jgrd.50691, 2013.

Vaughan, M. A., Powell, K. A., Winker, D. M., Hostetler, C. A., Kuehn, R. E., Hunt, W. H., Getzewich, B. J., Young, S. A., Liu, Z., and McGill, M. J.: Fully automated detection of cloud and aerosol layers in the CALIPSO lidar measurements, J. Atmospheric Ocean. Technol., 26, 2034-2050, doi:10.1175/2009JTECHA1228.1, 2009.

Vernier, J.-P., Fairlie, T. D., Natarajan, M., Wienhold, F. G., Bian, J., Martinsson, B. G., Crumeyrolle, S., Thomason, L. W., and Bedka, K.: Increase in upper tropospheric and lower stratospheric aerosol levels and its potential connection with Asian Pollution, J. Geophys. Res.-Atmos., 120, 1608-1619, doi:10.1002/2014JD022372, 2015.

Winker, D. M.: CALIPSO mission: spaceborne lidar for observation of aerosols and clouds (2003) Winker Publications Spie, in Proc. SPIE, Lidar Remote Sensing for Industry and Environment Monitoring III, vol. 4893, available at: http://spie.org/Publications/Proceedings/Paper/10.1117/ 12.466539\#.U7OSke5RVwE.citeulike, 2003.

Winker, D. M., Vaughan, M. A., Omar, A., Hu, Y., Powell, K. A., Liu, Z., Hunt, W. H., and Young, S. A.: Overview of the CALIPSO Mission and CALIOP Data Processing Algorithms, J. Atmospheric Ocean. Technol., 26, 2310-2323, doi:10.1175/2009JTECHA1281.1, 2009.

Young, S. A.: Analysis of lidar backscatter profiles in optically thin clouds, Appl. Opt., 34, 7019, doi:10.1364/AO.34.007019, 1995.

Young, S. A. and Vaughan, M. A.: The Retrieval of Profiles of Particulate Extinction from Cloud-Aerosol Lidar Infrared 
Pathfinder Satellite Observations (CALIPSO) Data: Algorithm Description, J. Atmospheric Ocean. Technol., 26, 1105-1119, doi:10.1175/2008JTECHA1221.1, 2009.

Young, S. A., Vaughan, M. A., Kuehn, R. E., and Winker, D. M.: The Retrieval of Profiles of Particulate Extinction from Cloud-Aerosol Lidar and Infrared Pathfinder Satellite Observations (CALIPSO) Data: Uncertainty and Error Sensitivity Analyses, J. Atmospheric Ocean. Technol., 30, 395-428, doi:10.1175/JTECH-D-12-00046.1, 2013.
Zhou, C., Dessler, A. E., Zelinka, M. D., Yang, P., and Wang, T.: Cirrus feedback on interannual climate fluctuations, Geophys. Res. Lett., 41, 9166-9173, doi:10.1002/2014GL062095, 2014. 